\title{
Medical services and injury management in Alpine skiing during the Winter Youth Olympic Games 2020 in Lausanne
}

\section{ELITE SPORTS / SPORTS AND YOUTH / SPORTS INJURY / TEAM MANAGEMENT}

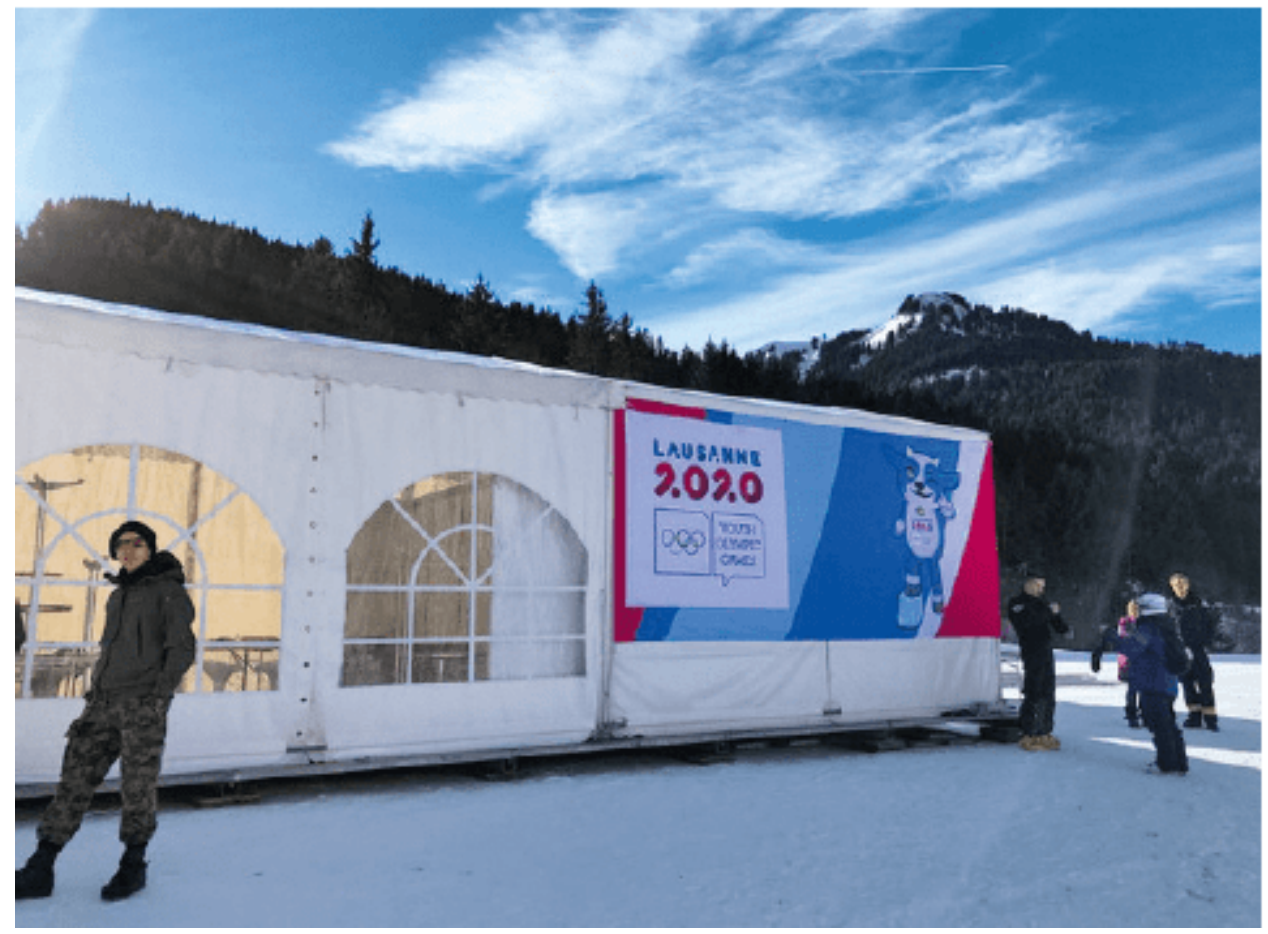

Goto Kazumi ${ }^{1}$, Menetrey Jacques1,2

${ }^{1}$ Centre for Sports Medicine and Exercise, Swiss Olympic Medical Center, Hirslanden Clinique La Colline, Geneva, Switzerland

${ }^{2}$ Orthopaedic Surgery Service, University Hospital of Geneva, Geneva, Switzerland

\section{Abstract}

Purpose: The Youth Olympic Games (YOG) are an elite sporting event for young athletes aged 15-18 years from all over the world. In the third Youth Olympic Winter Games, held in Lausanne in 2020, there were 16 disciplines and 81 events. In previous reports regarding YOG, injury risk was highest in the skiing events and alpine ski had a high rate, 14\% in 2012 and 12.9\% in 2016. The purpose of this report is to discuss the rescue organization, investigate the incidence of alpine ski injury during YOG 2020 and compare to previous reports. 
Methods: During the YOG 2020, we reviewed all alpine skiing injuries from 1 official training and 9 events. 77 men racers from 57 countries and 78 women racers from 54 countries have participated. We calculated injury incidence as the number of injuries in competition, training or in total during the game period divided by the respective number of participating athletes; with incidence values presented as injuries per 100 athletes. The injury rates per a game duration were compared among the each YOG games (2012, 2016, 2020) with use of the chi-square test. The injury rate between men and women was compared using the chi-square test as well.

Results: A total of 155 racers from 70 countries were registered for and exposed to the 7 competition days; 77 male (49.7\%) and 78 female athletes (50.3\%). There were 8 injuries (5 incidents) in 9 events.

Additionally, one injury occurred during the official practice. The injury rate was $3.9 \%$ in men and $7.7 \%$ in women. When comparing the previous YOG 2016 data, no significant differences were found both in male (3.9 vs $15.3 \%, p=0.186$ ) and female (7.7 vs $10.8 \%, p=0.178$ ), as well as YOG 2012 (vs $16.1 \%, p=0.067$ in male and vs $12.5 \%, \mathrm{p}=0.167$ in female).

Conclusion: Despite a very difficult course, injury rates were $7.7 \%$ in the female alpine skiers and $3.9 \%$ in the male alpine skiers during the 3rd Youth Olympic Winter Games in Lausanne 2020, which is comparable to the previous two YOG 2012 Innsbruck and 2016 Lillehammer event. The incidence and characteristics of injuries in training and competition varied between events.

\section{Résumé}

Objectif: Les Jeux Olympiques de la Jeunesse (JOJ) sont une manifestation sportive de haut niveau pour les jeunes athlètes de 15 à 18 ans, provenant du monde entier. Lors des 3e JOJ d'hiver de Lausanne, il y a eu 16 disciplines sportives, soit au total 81 compétitions. Lors des éditions précédentes des JOJ d'hiver, les rapports ont montré que le risque de blessure était le plus élevé dans les épreuves de ski, avec le ski alpin en tête: 14\% en 2012 et $12.9 \%$ en 2016. L'objectif de cet article est de discuter l'organisation des secours, d'explorer l'incidence des blessures dans les épreuves de ski alpin des JOJ 2020 et de comparer aux éditions précédentes.

Méthodes: Pendant les JOJ 2020, nous avons revu toutes les blessures du ski alpin sur les 9 épreuves et 1 entrainement officiel. 77 skieurs de 57 pays et 78 skieuses de 54 pays y ont participé. Nous avons calculé l'incidence des blessures en tant que nombre de blessures en compétition, entrainement et au total, pendant la période des Jeux, divisé par le nombre respectif des participants; les valeurs sont présentées comme blessures pour 100 athlètes. Le taux de blessure par événement est comparé entre les 3 éditions des JOJ (2012, 2016 et 2020) par le test de Chi carré, tout comme pour le taux de blessure entre les hommes et les femmes.

Résultats: Un total de 155 athlètes de 70 pays ont été enregistrés et ont participé aux 7 jours de compétition; 77 hommes (49.7\%) et 78 femmes (50.3\%). Il y a eu 8 blessures (5 incidents) en 9 épreuves. De plus, une blessure est survenue pendant l'entrainement officiel. Le taux de blessure était de $3.9 \%$ chez les hommes, et 7.7\% chez les femmes. En comparant avec les données des JOJ 2016, nous ne trouvons aucune différence significative chez les hommes ( 3.9 vs $15.3 \%, \mathrm{p}=0.186$ ) ou chez les femmes ( $7.7 \mathrm{vs} 10.8 \%, \mathrm{p}=0.178$ ), tout comme avec les JOJ 2012 (vs $16.1 \%, \mathrm{p}=0.067$ chez les hommes et vs $12.5 \%, \mathrm{p}=0.167$ chez les femmes). Conclusion: Malgré un parcours très difficile, le taux de blessure a été de $7.7 \%$ chez les skieuses alpines et de $3.9 \%$ chez les skieurs alpins pendant les $3^{\mathrm{e}}$ JOJ d'hiver de Lausanne 2020, ce qui constitue un taux 
comparable aux deux éditions précédentes (Innsbruck 2012 et Lillehammer 2016). L'incidence et les caractéristiques des blessures aux entrainements et en compétition variait toutefois en fonction des épreuves.

\section{Introduction}

The Youth Olympic Games (YOG) are an elite sporting event for young athletes aged 15-18 years from all over the world. But an event distinct from other youth sports competitions, as they also include a series of educational activities with three areas of focus: protecting the athletes, working on performance, and assisting the athletes outside sport [1]. The sports programme is mainly based on that of the Olympic Games. In addition, it includes exciting new sports, disciplines and formats, such as sport climbing, 3-x-3 basketball, 3-x-3 ice hockey and mixed gender and mixed National Olympic Committee (NOC) events. In the third Youth Olympic Winter Games, held in Lausanne in 2020, there were 16 disciplines and 81 events. In previous reports regarding YOG, injury risk was highest in the ski (28.6\% in 2016) and alpine ski had a high rate, 14\% in 2012 and 12.9\% in 2016 [2,3]. In addition to this high injury rates, it is also required to prepare a specific medical support in the unique environment of ski racing. Moreover, injury risk and patterns of young and adolescent athletes may vary and little is known about injury risk and illness occurrence in young elite winter sports athletes. The purpose of this report is to share our experience and challenges as rescue team, investigate the incidence of injury during YOG 2020, and compare it to previous reports.

\section{Medical services organization}

Organization of medical services was similar to a World Cup race including speed and technical disciplines. The service was therefore designed in accordance with the Fédération Internationale de ski (FIS) medical guide requirements and International Olympic Committee (IOC) medical commission recommendations. Eventually, the same as for an Olympic alpine skiing competition.

- The organisation on the hill was as followed:

- Four Doctors (2 orthopaedic surgeons, 1 sport physician, 1 anesthesiologist in the helicopter) highly experienced in alpine skiing medicine and racing. One top course medical care for athlete and ready to intervene on the course. One intermediate course station with 1 Doctor and 1 mobile rescue team. One finish-line medical care station.

- Two specialized nurses (one paediatric and one intensive care) located at the start (IC) and the finish line (paediatric)

- Three (speed disciplines) and 2 (technical disciplines) mobile rescues team were on the course. Each mobile team was composed of one ski patrol, one skiing paramedic, and a fully equipped sled with all materials necessary for stabilisation.

- One rescue helicopter on site

- One medically equipped and properly staffed tent based in the close vicinity of the finish area. In this unit, we had one Doctor, one specialized nurse, one sport physical therapist, four sanitary soldiers, 2 paramedics, and the evacuation coordinator (Fig. 1, 2a-b).

- One public facility for medical care of spectators staffed with a nurse

- One Advanced Life Support (ALS) ambulance for transport with a back-up plan if transport is used - One military ambulance for transfer and transport to the local medical center (very convenient) 
- One anti-doping facility fulfilling all requirements for the execution of anti-doping controls.

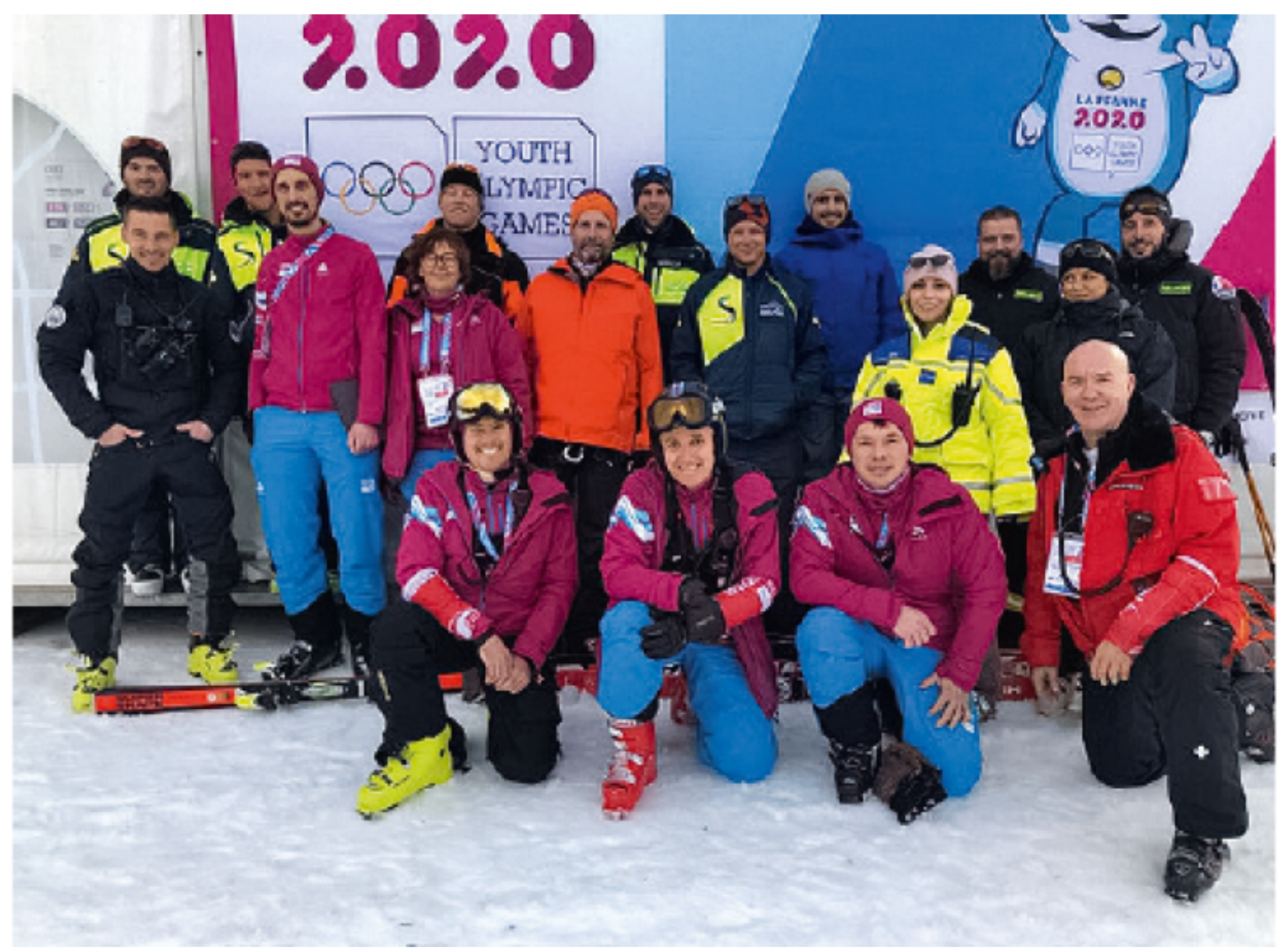

Figure 1: Our top-class multidisciplinary medical team. 


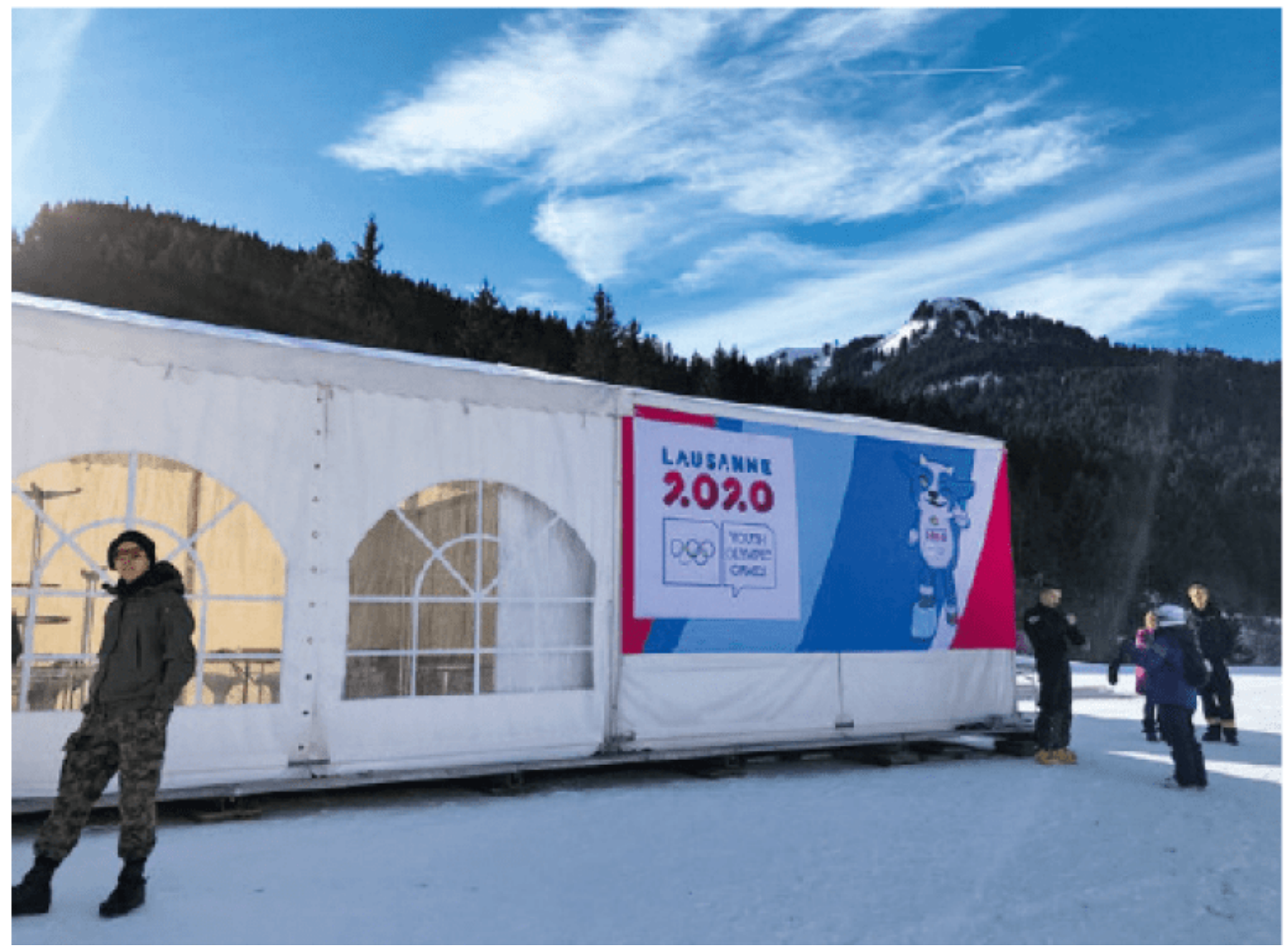

Figure 2a: Medical tent at the finish area. 


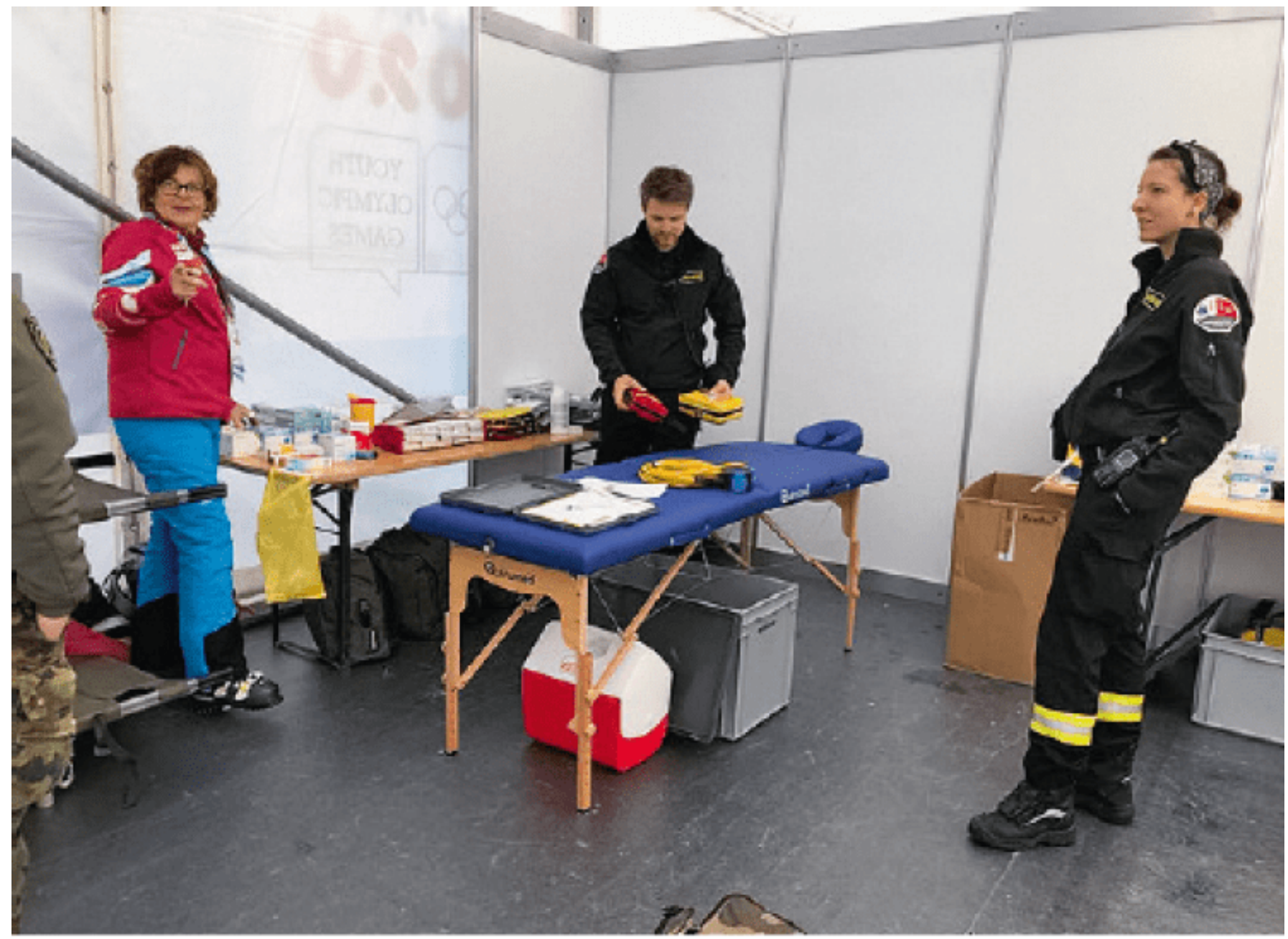

Figure 2b: Part of the medical equipment in the medical tent.

Far before the competition, an evacuation plan for injured athletes was established, availability of all secured facility was secured, a back-up plan/system was created to be operational in case of more or major evacuation was utilized, a separate plan of care was established for spectators and visitors, and the emergency medical plan has been several times reviewed with the Organizing committee. The chief of medical services has participated to team captain meetings (TCMs) the day before each event.

\section{Incidence of injury - Materials and Methods}

During the YOG 2020, we reviewed all alpine skiing injuries from 1 official training and 9 events. Our data base was completely anonymized during the events. There were an official super giant slalom (SG) training, men's and women's SG races, men's and women's alpine combined (AC) races, men's and women's giant slalom (GS) races, men's and women's slalom (SL) races, and a mixed gender parallel slalom (PSL-Team Event) race. The 77 men racers from 57 countries and 78 women racers from 54 countries participated. We recorded patients who were injured during competition or during official training. The definition of an injury was made in accordance with the previous YOG study [4] as following: injuries as new (pre-existing, not fully rehabilitated conditions were not recorded) or recurring (athletes having 
returned to full participation after a previous condition) musculoskeletal symptoms or concussions (injuries) or illnesses incurred in competition or training during the Lausanne YOG (10-16 January 2020) receiving medical attention, regardless of the consequences with respect to absence from competition or training. In cases where a single incident caused multiple injury types or affected multiple body parts, we recorded all diagnoses as separate injuries.

We calculated injury incidence as the number of injuries in competition, training or in total during the game period divided by the respective number of participating athletes; with incidence values presented as injuries per 100 athletes. The injury rates per a game duration were compared among each YOG (2012, 2016, 2020) with use of the chi-square test. The injury rate between men and women was compared using the chi-square test as well. A p-value of $<0.05$ was considered to be statistically significant. All statistical analyses were performed using R software packages (version 3.2.1; R Development Core Team).

\section{Results}

A total of 155 racers from 70 countries were registered for and exposed to the 7 competition days of the 2020 Lausanne Youth Olympic Winter Games. 77 male (49.7\%) and 78 female athletes (50.3\%). There were 8 injuries (5 accidents) in 9 events. Additionally, one injury occurred during the official practice. The injury rate was $3.9 \%$ in men and $7.7 \%$ in women. Details are shown in Table 1 and 2.

When comparing the previous YOG 2016 data, no significant differences were found both in male (3.9 vs $15.3 \%, \mathrm{p}=0.186$ ) and female ( 7.7 vs $10.8 \%, \mathrm{p}=0.178$ ), as well as YOG 2012 (vs $16.1 \%, \mathrm{p}=0.067$ in male and vs $12.5 \%, \mathrm{p}=0.167$ in female). Common to three Youth Olympic winter games, female skiers were more likely to present an injury, however, there were no significant difference $(p=0.495 \prec 2020>, 0.593 \prec 2016>, 0.609$ (2012)). This is shown in Table 3.

Table 1: Rates of injuries expressed as number of cases per 100 racers, separated for female and male racers participating in Youth Olympic Games 2020

\begin{tabular}{|l|l|l|l|}
\hline & \multicolumn{3}{|c|}{ Registered athletes } \\
\hline & Female & Male & Total \\
& $n$ & $n$ & $n$ \\
\hline Super giant slalom & 62 & 64 & 126 \\
\hline Alpine combined & 62 & 64 & 126 \\
\hline Giant slalom & 78 & 77 & 155 \\
\hline Slalom & 78 & 77 & 155 \\
\hline Parallel slalom & 16 & 16 & 32 \\
\hline Total & 78 & 77 & 155 \\
\hline
\end{tabular}

\begin{tabular}{|l|l|l|}
\hline \multicolumn{3}{|c|}{ Injuries } \\
\hline $\begin{array}{l}\text { Female } \\
n(\%)\end{array}$ & $\begin{array}{l}\text { Male } \\
n[\%]\end{array}$ & $\begin{array}{l}\text { Total } \\
n(\%)\end{array}$ \\
\hline $2(3.2)$ & $1^{*}\left[1.6^{*}\right]$ & $3(2.4)$ \\
\hline $4(5.1)$ & & $4(2.6)$ \\
\hline & $1(1.3)$ & $1[0.6]$ \\
\hline $6(7.7)$ & $1(6.3)$ & $1[3.1]$ \\
\hline & $3(3.9)$ & $9(5.8)$ \\
\hline
\end{tabular}

* An injury during the official training of super giant slalom 
Table 2: All incidents during the Youth Olympic Games 2020

\begin{tabular}{|l|l|l|l|}
\hline Patient Number & Sex & Event & Injury \\
\hline 1 & M & SG training & Thumb sprain \\
\hline 2 & F & SG & Fibula fracture, face laceration \\
\hline 3 & F & GS & ACL injury, thumb bruise, tooth injury \\
\hline 4 & F & GS & ACL injury \\
\hline 5 & M & SL & MCL injury \\
\hline 6 & M & PSL & Elbow bruise \\
\hline
\end{tabular}

SG: super giant slalom, GS: giant slalom, SL: slalom, PSL: parallel slalom, ACL: anterior cruciate ligament, MCL: medial collateral ligament

Table 3: Comparison between this study and previous Youth Olympic Games

\begin{tabular}{|c|c|c|c|c|c|c|}
\hline & \multicolumn{3}{|c|}{ Registered athletes } & \multicolumn{3}{|c|}{ Injuries } \\
\hline & $\begin{array}{l}\text { Female } \\
n\end{array}$ & $\begin{array}{l}\text { Male } \\
n\end{array}$ & $\begin{array}{l}\text { Total } \\
\mathrm{n}\end{array}$ & $\begin{array}{l}\text { Female } \\
\mathrm{n}(\%)\end{array}$ & $\begin{array}{l}\text { Male } \\
\mathrm{n}[\%]\end{array}$ & $\begin{array}{l}\text { Total } \\
\text { n }[\%]\end{array}$ \\
\hline Lausanne 2020 & 78 & 77 & 155 & $6(7.7 \%)$ & $3[3.9 \%]$ & $9[5.8 \%]$ \\
\hline Lillehammer 2016 & 59 & 65 & 124 & $9[15.3 \%]$ & 7 [10.8\%] & $16(12.9 \%)$ \\
\hline Innsbruck 2012 & 56 & 64 & 120 & 9 [16.1\%] & 8 [12.5\%] & $17[14.2 \%]$ \\
\hline
\end{tabular}

\section{Discussion}

Being involved in the medical service of Lausanne 2020 YOG was a fantastic experience and a real professional challenge. The key words of this intense period have been adaptability and flexibility. In which aspect this experience was different from a world-class event organization, we have previously worked on?

(1) Emotion, at all level of the event, everything was more emotional, and of course, when an injury occurred it raised up even more, increasing the stress and the burden on the medical team. To face such situations, you need to have experienced collaborators with not only an excellent professional expertise, but also with a great know-how too. Important to say, the FIS medical supervisor has been instrumental and of great help.

(2) General organization, contrary to the usual organization where you design the service, recruit your people, and implement it accordingly yourself, everything here has been decided and put in place by a central organizing committee. Well done by the way, but it makes it very challenging to provide a topperformance during the first days of the event.

(3) Human resources, with the volunteering system, you have not selected your staff yourself and said staff changed almost every day. Most of them were great, though. However, in such a demanding and risky sport as alpine skiing racing, it may make your medical team inconsistent from day to day. Especially because experience is one of the major factors in your medical performance. In this situation, it is a must to brief in depth the newcomers and put them back on track every morning.

(3) Environment, it is what transforms a minor rescuing process in a very complicated one. For example, the intermediary part of the course was so steep and icy, that it was just impossible to rescue anyone with a sled in this section. So, we had to readjust our protocols day after day to adapt to the conditions, and in this respect, this was such a luxury to have the REGA helicopter on site. The tougher the environment, the greater the experience and expertise of your staff should be. In alpine skiing, a good ski patrol plus a paramedic with experience in the sport plus a Doctor with good ski ability and extensive experience make a good team, but this team must be assisted by a mountain-specialized rescue helicopter. 
Sports medicine organizations should not give up on-field sports/athletes rescuing and leave it to a paramedic company. Rescuing athletes is a very specific task that requires in depth knowledge of the sport, specific adaptations to the environment (emotion, nature, surface, spectators, TV), special training and expertise in Advanced Life Support and Emergency Management. This is by essence a team work. However, sports medicine Doctors should be fully trained and keep educating themselves through handson team physician courses, regular contact with emergency cases and/or visits to emergency stations. The most important finding of the injury study was that $7.7 \%$ of the female athletes and $3.9 \%$ of the male athletes suffered from injury, respectively. Although there was no significant difference, the frequency of injuries were smaller than previous Youth Olympic Games both 2012 and 2016, and the female ski racers were more likely to get injured in the three YOGs. These are remarkable results if we consider the difficulty of the course, which was steep, glossy, super frozen and hard, more difficult than certain WC courses according to the FIS technical delegate. Women were clearly less comfortable on this tough course, and it may explain the higher number of injuries in women.

There are many epidemiological studies for alpine ski injury previously. The difference of the injury rate between male and female vary widely depending on the cohort [5]. In a study that surveyed the six consecutive seasons of World Cup [6], the relative injury rate, expressed as injuries per 1000 runs, was higher for men (11.3, 95\% CI 11.1 to 11.5 ) than women (7.1, 95\% CI 7.0 to 7.3), RR 1.58 (95\% CI 1.22 to 2.04). For time-loss injuries only, the corresponding incidence was 9.1 injuries/1000 runs for men versus 5.3 for women (RR 1.72). According to the recent review from 64,667 ski injuries7, most injuries occur to the lower extremity, with reports ranging from $43 \%$ to $77 \%$ of all alpine skiing-related injuries. This is followed by injuries to the upper extremity, which account for approximately $14 \%$ of injuries and primarily involve the thumb and shoulder. Head and neck injuries account for $13 \%$ of all injuries. Among the lower extremity, the knee is the most common site and the most common type of knee injuries are knee ligament injuries involving anterior cruciate ligament (ACL) and/or medial collateral ligament (MCL). Stevenson et al [8] surveyed 404 alpine ski racers in Vermont and found a 2.3 times increased likelihood for knee injury in female racers compared with male racers, and a 3.1 times increased likelihood for ACL injury in females compared with males. Raschner et al [9] identified a 2.3 times increased risk of ACL injury in females aged 14 to 19 years compared with their male counterparts ( $<0.05$; 95\% CI, 1.3-4.2). It was suggested that young female athletes are not always sufficiently prepared for elite ski racing and may therefore be at higher risk of injury [10].

On the other hand, studies on US ski patrols/instructors [11] suggest that there is no sex- difference in the risk of knee/ACL injuries among elite skiers. Bere et al [6] also supported that there was no sex difference in the risk of knee/ACL injuries (women: 5.4 injuries/100 athletes/season and men: 5.5) in World Cup skiers. In an evaluation of an injury database of 70 elite alpine skiers from 2004 through 2013, Schmitt et al [12] found that a higher skier seasonal ranking (FIS score at time of injury) was significantly associated with a history of knee injury. In their study, the difference of incidence of ACL injuries between injured male and female athletes was statistically not significant. According to 2 studies by Westin et al [13,14], both males and females were more likely to sustain knee ligament injuries to the left rather than the right leg, although leg dominance was not discussed. Flørenes et al [15], in their study on alpine skiers of the French national team, reported that there was no difference in the occurrence rate of ACL tears between technical and speed disciplines. In men, incidence between the number of ACL injuries and the number of skieryears in technical and speed disciplines were the same. In women, there was a slightly higher incidence in 
speed disciplines as compared to technical disciplines.

Although it is a retrospective study with a smaller sample compared to previous epidemiological studies and a short period of time during YOG 2020, we believe that this report must be useful as there are few reports of ski injuries at the top level of this age.

\section{Conclusion}

Despite a very difficult course, injury rates were $7.7 \%$ in the female alpine skiers and $3.9 \%$ in the male alpine skiers during the 3rd Youth Olympic Winter Games in Lausanne 2020, which is comparable to the previous two YOG 2012 Innsbruck and 2016 Lillehammer event. The incidence and characteristics of injuries in training and competition varied between events.

\section{List of abbreviations}

SG: super giant slalom

GS: giant slalom

SL: slalom

AC: alpine combined

PSL: parallel slalom

ACL: anterior cruciate ligament

MCL: medial collateral ligament

\section{Conflict of interest}

The authors declare that they have no competing interests.

\section{First author}

Kazumi Goto

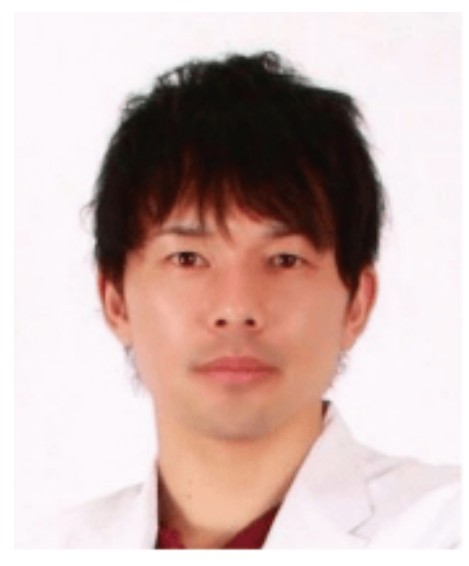




\section{Corresponding author}

Jacques Menetrey

Centre de Médecine du Sport

et de l'Exercice (CMSE)

Hirslanden Clinique La Colline

Chemin Thury 7A

CH-1206 Genève

Ph: +41-22-702-2543

Email: cabinet.menetrey@hirslanden.ch

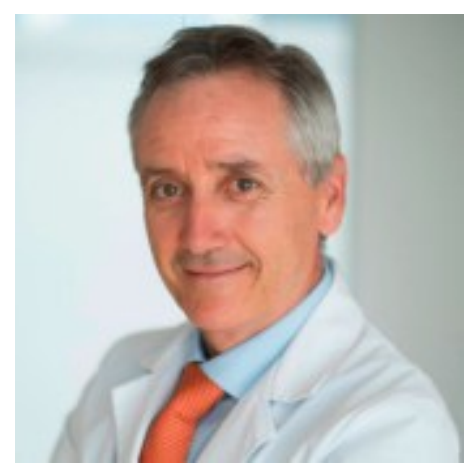

\section{References}

1. https://www.olympic.org/news/what-is-yog

2. https://www.lausanne2020.sport/en

3. Ruedl G, Schobersberger W, Pocecco E, et al Sport injuries and illnesses during the first Winter Youth Olympic Games 2012 in Innsbruck, Austria British Journal of Sports Medicine 2012;46:1030-1037.

4. Steffen K, Moseid CH, Engebretsen L, Søberg PK, Amundsen O, Holm K, Moger T, Soligard T. Sports injuries and illnesses in the Lillehammer 2016 Youth Olympic Winter Games. British Journal of Sports Medicine 2017; 51:29-35.

5. Tarka MC, Davey A, Lonza GC, O’Brien CM, Delaney JP, Endres NK. Alpine Ski Racing Injuries. Sports Health. 2019;11(3):265-271. doi:10.1177/1941738119825842

6. Bere T, Flørenes TW, Nordsletten L, Bahr R. Sex differences in the risk of injury in World Cup alpine skiers: a 6-year cohort study. Br J Sports Med. 2014; 48:36-40.

7. Davey A, Endres NK, Johnson RJ, Shealy JE. Alpine Ski Racing Injuries. Sports Health. 2019;11(1):18-26. doi:10.1177/1941738118813051

8. Stevenson H, Webster J, Johnson R, et al. Gender differences in knee injury epidemiology among competitive alpine ski racers. Iowa Orthop J 1998;18:64-6.

9. Raschner C, Platzer HP, Patterson C, et al. The relationship between ACL injuries and physical fitness in young competitive ski racers: a 10 year longitudinal study. Br J Sports Med 2012;46:1065-71.

10. Spörri J, Kröll J, Amesberger G, Blake OM, Müller E. Perceived key injury risk factors in World Cup alpine ski racing-an explorative qualitative study with expert stakeholders. Br J Sports Med 2012; 46:1059-1064.

11. Viola RW, Steadman JR, Mair SD, et al. Anterior cruciate ligament injury incidence among male and female professional alpine skiers. Am J Sports Med 1999;27:792-5.

12. Schmitt et al. Investigating physical fitness and race performance as determinants for the ACL injury risk in Alpine ski racing. BMC Sports Science, Medicine and Rehabilitation (2016) 8:23

13. Westin M, Alricsson M, Werner S. Injury profile of competitive alpine skiers: a five-year cohort study. Knee Surg Sports Traumatol Arthrosc. 2012;20:1175-1181.

14. Westin M, Reeds-Lundqvist S, Werner S. The correlation between anterior cruciate ligament injury in elite alpine skiers and their parents. Knee Surg Sports Traumatol Arthrosc. 2016;24:697-701.

15. Flørenes TW, Bere T, Nordsletten L, Heir S, Bahr R. Injuries among male and female World Cup alpine skiers. Br J Sports Med. 2009 Dec;43(13):973-8 
ALPINE SKI RACE SKI INJURY SPORTS INJURY IN YOUNG ELITE ATHLETES YOUTH OLYMPIC WINTER GAMES 